\title{
The Impact of Object Complexity on Visual Working Memory Capacity
}

\author{
Xiaoxi Chen', Bin Li1 ${ }^{12 *}$, Yaozhong Liu ${ }^{*}$ \\ ${ }^{1}$ Management School, Jinan University, Guangzhou, China \\ ${ }^{2}$ The Institute of Enterprise Development, Jinan University, Guangzhou, China \\ Email: ^bingoli@jnu.edu.cn, *liuyaozhong518@163.com
}

How to cite this paper: Chen, X. X., Li, B. \& Liu, Y. Z. (2017). The Impact of Object Complexity on Visual Working Memory Capacity. Psychology, 8, 929-937. https://doi.org/10.4236/psych.2017.86060

Received: March 17, 2017

Accepted: April 27, 2017

Published: April 30, 2017

Copyright (c) 2017 by authors and Scientific Research Publishing Inc. This work is licensed under the Creative Commons Attribution International License (CC BY 4.0).

http://creativecommons.org/licenses/by/4.0/

\begin{abstract}
The capacity of visual working memory (VWM) is regarded as one of the central themes in working memory. Related studies-on cognitive psychology and neuroscience level focused on the flexibility of capacity of working memory and the influencing factors. The current study aimed at the relationship of object complexity and VWM capacity, which used change detection paradigm in order to reveal the mechanism of object representation in visual working memory. We explored the impact of complexity on capacity of VWM by different-complexity-level Snodgrass line drawings. Participants were required to remember 2,3 or 5 objects at the same time. In experiment 1 , we set the initial stimulus exposure time at $500 \mathrm{~ms}$ to investigate the complexity effect. Then we varied the duration of the initial stimulus exposure time to $250 \mathrm{~ms}, 750 \mathrm{~ms}$ to rule out perception constraint and the test the time course of the complexity effect. We found that the middle-level-complexity object had the best performance which could be named as "middle complexity effect". This effect was not the result restrained by the perception and disappeared when the exposure time was prolonged to $750 \mathrm{~ms}$.
\end{abstract}

\section{Keywords}

Visual Working Memory, Complexity, Capacity, Representation

\section{Introduction}

Working memory (Baddeley \& Hitch, 1974) is a crucial concept in cognitive psychology and cognitive neuroscience, which underpins the capacity for complex cognitive tasks, such as reasoning, learning, and comprehension (Baddeley, 2006). It is assumed to be a limited capacity system for the temporary storage and manipulation of information, and more and more models emphasized both processing, storage function and the difference function of processing different 
type of information.

According to related research findings, visual working memory can be divided into spatial working memory, and object (Smith et al., 1995)/visual (Courtney et al., 1997; Ungerleider et al., 1998) working memory. Visual working memory (VWM) is responsible for the visual/object information. Visual working memory capacity is of great interest because it is strongly correlated with overall cognitive ability, can be understood at the level of neural circuits, and is easily measured. Recent studies from human psychophysical literature have revealed some nature of human VWM. Cowan (2001) analyzed a wide variety of data on capacity limits and suggested a single, central capacity limit averaging about four chunks. This is named as magic number " 4 " and already has significant behavioral consequences. Using change blindness paradigm, Luck and Vogel suggested that VWM could store 4 integrated objects and the capacity of visual working memory must be understood in terms of integrated objects. Alvarez and Cavanagh (2004) found both the visual information load and total number of objects (set size) restrained the capacity of visual short-term memory VWM. New evidence shows that VWM capacity is modulated by the complexity of visual objects encoded (Xu, 2002; Song \& Jiang, 2006).

Complexity has two properties: one is by physics and the other is by psychology. Current researches usually utilize figures or other abstract pictures which share little common with the real world and have low ecological validity. Then we wonder how the real world represents in our VWM or what the specific capacity is? Here we intend to measure the VWM capacity for real objects in terms of standardized Snodgrass line drawings to answer this question. The materials were chosen from the picture base set by Snodgrass \& Vanderwart (1980), standardized by Chinese researchers Shu et al. (1989) and then followed Zhang and Yang (2003). They assessed four-indexes: name agreement, familiarity, image agreement, and visual complexity of these line drawings using a five-point scale on Chinese participants.

In current studies, researchers using figures judge the object simple or complex by sensibility through change detection paradigm. If it contains only one feature, it is simple and if it contains two bound features, it is complex. The definition of complexity remains vague. Alvarez and Cavanagh (2004) revealed the linear relationship between the complexity of visual object (estimated with its visual search rate) and its VWM capacity. The visual complexity of this measurement method was a kind of indirect way, and also mixed the composition of learning because the search and change-detection task are using the same target objects. Cao and Li (2005) investigated the relationship between the complexity of line drawing and the visual search task. The results showed that when the interference of the complexity unchanged, the reaction of visual search function was asymmetric around the $U$ curve as the complexity increased. This meant that middle-level complexity for line drawings showed the best visual search efficiency (also see Cao \& Lin, 2005). Psychologically, if object complexity capacity can directly act on capacity, the middle-complexity will also exist in VWM. In 
this study, we conducted experiments to test the influence of psychological complexity on VWM and explored the advantage of middle-level complexity effect in VWM processing.

\section{Experiment 1}

\subsection{Method}

Participants. 21 undergraduate students (male $=13$, average age $=22.1$ ) from the South China Normal University took part in return for monetary payment or course credit. Participants in this and all subsequence experiments are naive to the experimental paradigm and report normal or corrected-to-normal color vision.

Apparatus and stimulus. Visual stimulus for this and all subsequence experiments are displayed on a gray background on a 15 ", $1024 \times 768$ computer screen running an E-Prime 1.2 (Psychology Software Tools, 1996-2006). Here we used the Snodgrass line drawings (Snodgrass et al., 1980; Zhang et al., 2003) chosen from the picture set standardized by Zhang and Yang. We computed their three indexes: complexity, familiarity, visual image agreement of the three group pictures. Here we selected lowest, the middle and the highest 20 pictures to form three groups of the material, with the visual complexity score: 1.08 $1.62,2.85-3.00,3.67-4.23$, respectively. One Way ANOVA revealed a significant effect in complexity $(P<0.001)$ and no significance in familiarity and visual image agreement $(P>0.05)$ of the three groups. The picture each subtended a visual angle of $3^{\circ} \times 3^{\circ}$. In the initial display, all drawings were scatted on a round with a radius of $4.5^{\circ}$. All the pictures in the initial array and the test stimulus within the same trail were from the same level (Figure 1).

Design. A two-factor within-subject design: complexity (low, middle, high) $\times$ set size $(2,3,5)$ was used. There were 20 trails for each condition. At test, participant judge whether the probe was the same as one of the items in initial display. Accuracy was the dependent measure and used Cowan' $\mathrm{K}$ equation to calculate the capacity of VWM: K = (Hit rate + Correct Rejection rate -1$) \times$ Set size. In each trail, the sequence of displays for all experiments (unless otherwise noted) was as follows.

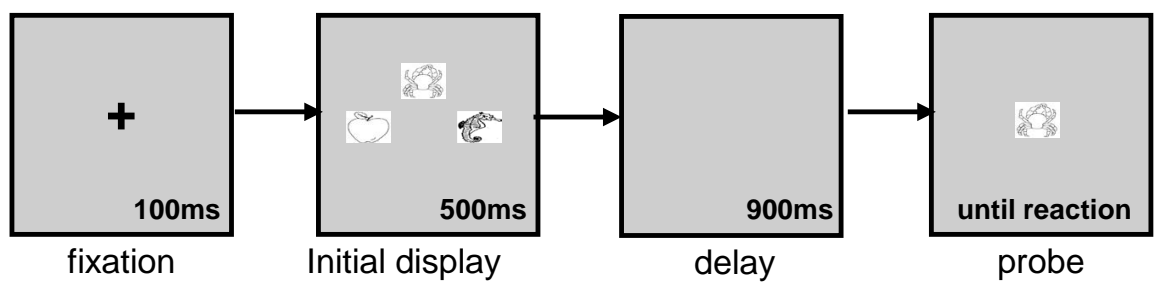

Figure 1. Examples of experimental paradigms in Experiment 1. A small, black, warning cross was presented at center screen for $100 \mathrm{~ms}$. This was followed by the initial display of color squares for $500 \mathrm{~ms}$, then a $900 \mathrm{~ms}$ blank interval, and finally by a test display that remained present until a response is made. At test phase, participant indicates whether the probe was the same as or different from one of the items in initial display by a keypress. On $50 \%$ of the trails the probe was a new color haven't present on the screen. 
General Procedure. The following general procedure applied to all experiments. Participants repeated the phrase "abc" during the initial display and memory delay period. They stopped to make a choice when the probe appeared. At the beginning of the experiment, participants read through a detailed description of the study. Then they practiced 2 trails of each condition under the supervision of the experimenter and were given feedbacks on their reactions. They started the formal experiment on condition that their accuracy in practice reaches 80 percent or higher.

\subsection{Results and Discussion}

Increased memory load (set size) led to a great decline in accuracy rate and VWM capacity (Table 1 and Figure 2).

A $3 \times 3$ repeated ANOVA on VWM capacity revealed a significant main effect of the complexity $F(2,40)=10.22, p<0.001$, set seize $F(2,40)=19.62, p<0.001$, and the interaction between them $F(4,80)=2.835, p<0.05$ (Figure 2). Pairwise comparisons shown significant differences between middle complexity and the other two levels and all comparisons between set sizes were also significant (all $p<$ 0.05). The middle complexity object showed an advantage in VWM.

\section{Experiment 2}

Considering the pictures using here were rather complex, and the duration of initial array was the same $500 \mathrm{~ms}$, people argued that there might be a perception

Table 1. Accuracy rate and VWM capacity (mean and SD) for different object complexity level in experiment 1.

\begin{tabular}{ccccccc}
\hline \multirow{2}{*}{ Complexity } & \multicolumn{7}{c}{ Set Size } \\
\cline { 2 - 7 } & \multicolumn{7}{c}{2} & \multicolumn{2}{c}{3} \\
\hline \\
\cline { 2 - 7 } Accuracy & VWM & Accuracy & VWM & Accuracy & VWM \\
\hline High & 0.91 & $1.68(0.26)$ & 0.85 & $2.13(0.51)$ & 0.70 & $2.07(1.06)$ \\
Middle & 0.92 & $1.76(0.19)$ & 0.90 & $2.46(0.35)$ & 0.78 & $2.90(0.74)$ \\
Low & 0.92 & $1.69(0.24)$ & 0.86 & $2.17(0.44)$ & 0.70 & $2.33(1.07)$ \\
\hline
\end{tabular}

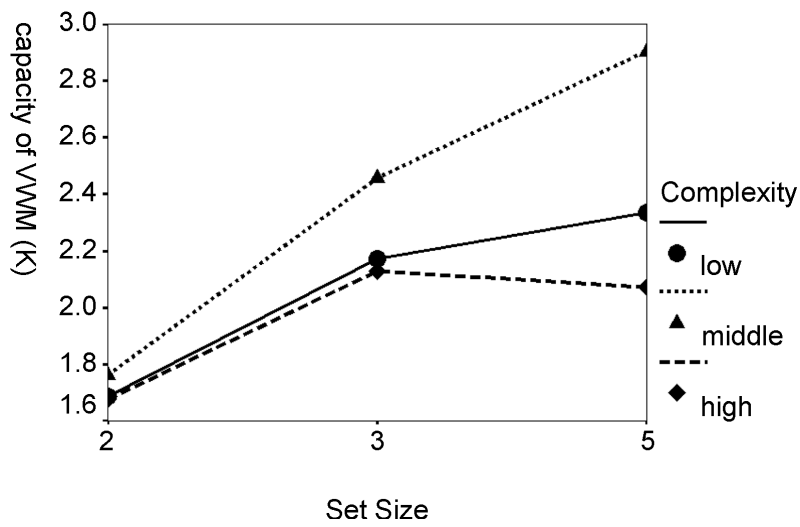

Figure 2. VWM capacity declined with set size in visual display in experiment 1 . 
constraint. Participants probably didn't see all the pictures within the duration of initial display, so this was not the VWM measurement but the perception effect. To test this possibility, we conducted experiment 2 .

\subsection{Method}

Participants. 19 undergraduate students $($ male $=10$, average age $=21.3)$ of South China Normal University took part in return for monetary payment or course credit. They gave informed consent according to procedures approved by the Jinan University.

Stimulus The same as experiment 1.

Design. A two factors within-subject design: complexity (low, middle, high) $\times$ set size $(2,3,5)$ was used. To rule out the interference of perception factor, the duration of sample array was reduced to $250 \mathrm{~ms}$.

\subsection{Results and Discussion}

The data analysis was the same as what has been illustrated in experiment 1 . According to Luck and Vogle (1997), the perception may be an interference factor in storage of VWM. To estimate this effect, we used the shortest duration of change detection paradigm $250 \mathrm{~ms}$ in Experiment 2. Increased memory load (set size) also led to a similar decline in accuracy rate and VWM capacity (Table 2 and Figure 3).

Table 2. Accuracy rate and VWM capacity (mean and SD) for different object complexity level in experiment 2 .

\begin{tabular}{ccccccc}
\hline \multirow{2}{*}{ Complexity } & \multicolumn{7}{c}{ Set Size } \\
\cline { 2 - 7 } & \multicolumn{7}{c}{2} & \multicolumn{2}{c}{3} & & 5 \\
\hline & Accuracy & VWM & Accuracy & VWM & Accuracy & VWM \\
\hline High & 0.89 & $1.55(0.25)$ & 0.82 & $1.93(0.65)$ & 0.72 & $2.53(0.48)$ \\
Middle & 0.95 & $1.81(0.30)$ & 0.85 & $2.16(0.43)$ & 0.78 & $2.90(0.72)$ \\
Low & 0.92 & $1.67(0.42)$ & 0.86 & $2.21(0.52)$ & 0.73 & $2.31(0.73)$ \\
\hline
\end{tabular}

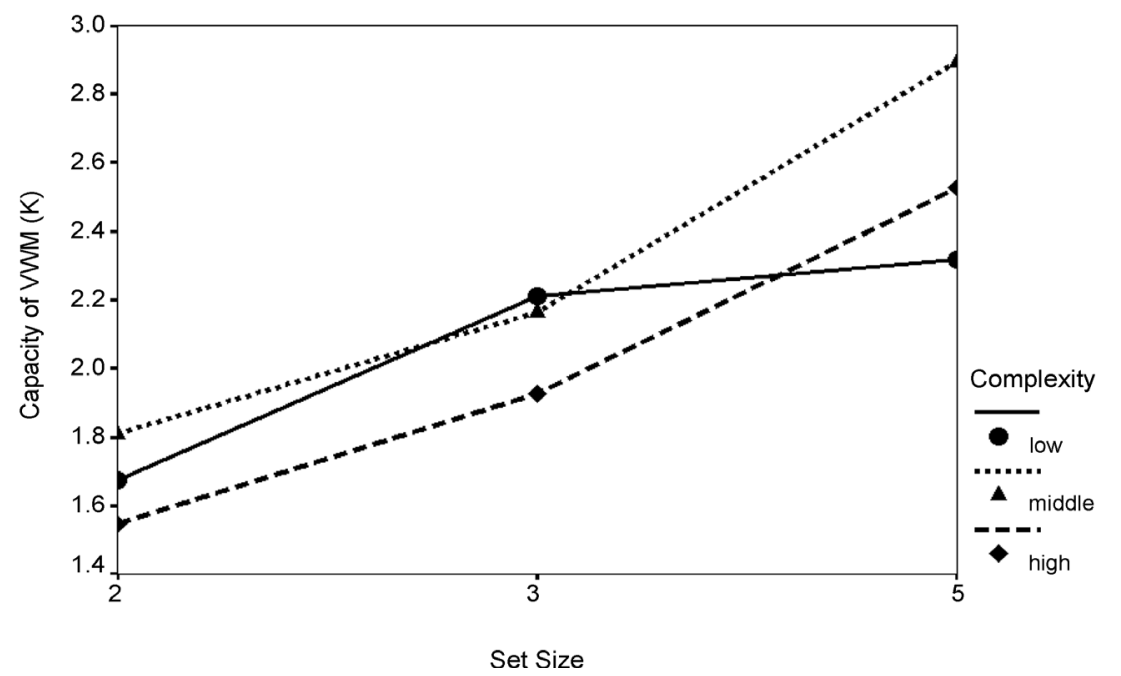

Figure 3. VWM capacity declined with set size in visual display in experiment 2. 
A $3 \times 3$ repeated ANOVA on VWM capacity revealed a significant main effect of the complexity $F(2,36)=6.044, p<0.05$, set seize $F(2,36)=62.995, p<0.001$, and the interaction between them was not significant, $F(4,72)=1.880, p=0.123$. The middle-level objects were still no less stored than objects of other complexity levels.

\section{Experiment 3}

We believed this middle-complex effect had its own course and would get weak or disappear when the duration of initial array reached long enough. Thus we conducted this experiment to estimate this prediction.

\subsection{Method}

Participants. 19 undergraduate students (male $=11$, average age $=21.7$ ) took part in return for monetary payment or course credit.

Stimulus. The same as experiment 1.

Design. A two factors within-subject design: complexity (low, middle, high) $\times$ set size $(2,3,5)$ was used. To explore the course of middle-complex effect, the duration of sample array was last to $750 \mathrm{~ms}$.

\subsection{Results and Discussion}

The data analysis was the same as what has been illustrated in experiment 1 . Increased memory load (set size) also led to a similar decline in accuracy rate and VWM capacity (Table 3 and Figure 4).

A $3 \times 3$ repeated ANOVA on IC rate revealed a significant main effect of the complexity $F(2,36)=1.398, p>0.05$, set seize $F(2,36)=62.324, p<0.001$, and the interaction between them $F(4,72)=1.59, p=0.186$. Pairwise comparisons shown significant differences between all set sizes but none of complexity levels. The advantage of middle complexity disappeared.

\section{General Discussion}

This article aimed at exploring the mechanism of capacity and representation in VWM by change detection paradigm. We believed complexity would influence the VWM capacity, so object representation in VWM was feature-based (Experiment 1 to 3 ). The unit of storage was feature, and each dimension had its own

Table 3. Accuracy rate and VWM capacity for different object complexity level in experiment 3 .

\begin{tabular}{ccccccc}
\hline \multirow{2}{*}{ Complexity } & \multicolumn{7}{c}{ Set Size } \\
\cline { 2 - 7 } & \multicolumn{7}{c}{2} & \multicolumn{2}{c}{3} & & \\
& Accuracy & VWM & Accuracy & VWM & Accuracy & VWM \\
\hline High & 0.94 & $1.78(0.20)$ & 0.88 & $2.26(0.51)$ & 0.81 & $3.08(0.89)$ \\
Middle & 0.97 & $1.87(0.18)$ & 0.94 & $2.67(0.35)$ & 0.79 & $2.95(0.81)$ \\
Low & 0.92 & $1.70(0.25)$ & 0.91 & $2.48(0.34)$ & 0.79 & $2.90(0.91)$ \\
\hline
\end{tabular}




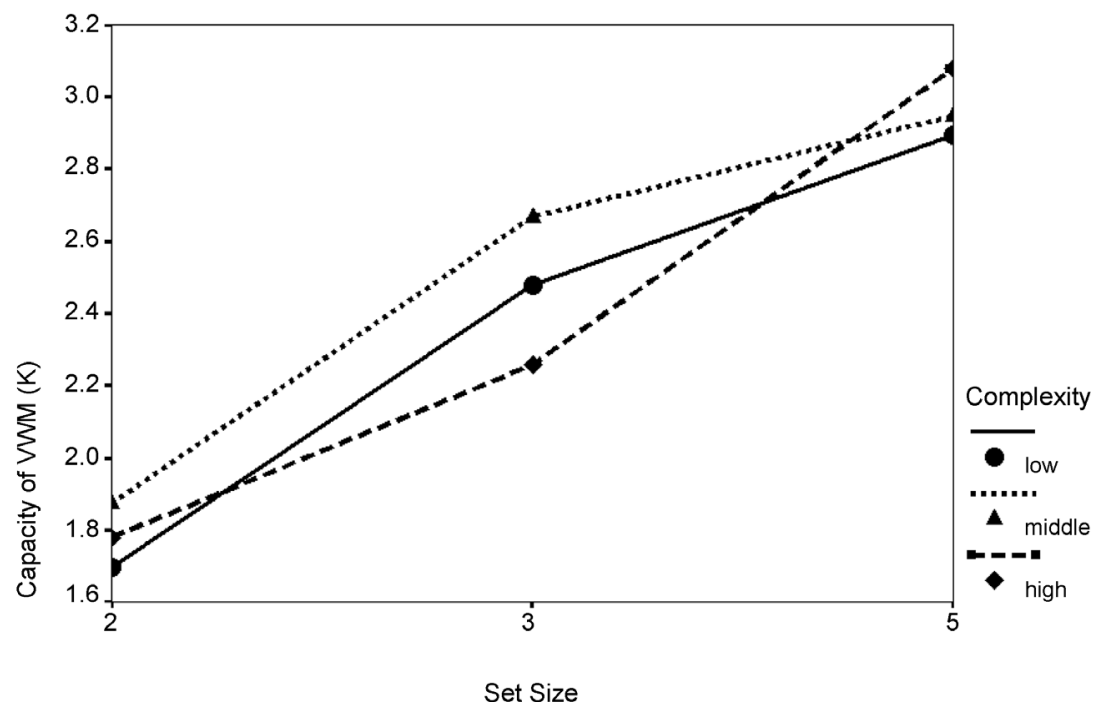

Figure 4. VWM capacity declined with set size in visual display in experiment 3.

storage subsystem, so different features were stored separately. Wheeler and Treisman (2002)'s dual-storage model was a support to this view.

Object representation and its capacity in VWM both refers to the unit of storage. Here we assume the unit is feature of each object, but not the whole features object contains. For simple figures, features can be easily found together; however, in line drawings of real object, features are mixed together. It is hard to count and not possible to remember all details. Alvarez and Cavanagh (2008) suggested a core set of features, and other not necessary information is not encoded or soon lost after encoding. This partly explains why we can remember real, as well, complex objects in daily life.

We found that we manipulated the features containing in each object, then the capacity observed declined systemically. However, people do not usually count the features of object; they just judge it "simple" or "complex". Thus, this can be called psychological view of complexity. It is relative to the physical method above. Therefore, asking people to assess pictures in a scale can tell us how complexity assessment influences the VWM. Concerning the middle-complexity effect in visual search task and the relationship between the visual search rate and the capacity in VWM, we also found the middle-complexity effect in VWM task.

We can explain this effect in VWM by three ways. First, middle-level-complex object commonly contains less detail than the high-level one, as a result the interference of unrelated information is less when encoding. From a resource viewpoint, the competition between irrelevant information and the main task of competition will cause a decline in behavior well-being. Second, we assume that the core set of pictures comes into storage, which will be the effective clues of extraction phase. Middle-level-complex object has a larger core set than that of low-level one; hence, it has more clues for getting back. Third, middle-complex effect may be an outcome of revolution. This biological view needs more physiological evidences.

Limitations of this study include stimuli used in all experiments are from the 
same line drawing database. Line drawings lacks of ecological validity, so further researches should use pictures of real scene and test the middle-level advantage effect.

\section{Conclusion}

Visual working memory capacity is influenced by the psychological complexity of objects to be processed. What's more, middle-level complex objects have advantage in processing and showed higher VWM capacity than low and high complex ones. Finally, the middle-level complexity advantage effect is moderated by encoding time.

\section{Fund}

This research was supported by grants from the National Natural Science Foundation of China (71601084), National Natural Science Foundation of Guangdong in China (2016A030313113), Humanity and Social Science Youth foundation of Ministry of Education of China (14YJCZH068).

\section{References}

Alvarez, G. A., \& Cavanagh, P. (2004). The Capacity of Visual Short-Term Memory Is Set Both by Visual Information Load and by Number of Objects. Psychological Science, 15, 106-111. https://doi.org/10.1111/j.0963-7214.2004.01502006.x

Alvarez, G. A., \& Cavanagh, P. (2008). Visual Short-Term Memory Operates More Efficiently on Boundary Features than It Does on Surface Features. Perception \& Psychophysics, 70, 346-364.

Baddeley, A. D., \& Hitch, G. J. (1974). Working Memory. In G. H. Bower (Ed.), The Psychology of Learning and Motivation: Advances in Research and Theory (Vol. 8, pp. 47-90). New York, NY: Academic Press.

Cao, L. R., \& Li, Y. M. (2005).The Influence of Figures Complexity on Visual Search. In The tenth National Psychology Conference (p. 234).

Cao, X. H., Lin, L. B., \& Liu, Z. J. (2005). The Influence of Figures Complexity and Cognitive Style to the Performance of Visual Search. Chinese Journal of Ergonomics, 11, 8 10. (In Chinese)

Courtney, S. M., Ungerleider, L. G., Keil, K. et al. (1997). Transient and Sustained Activity in a Distributed Neural System for Human Working Memory. Nature, 386, 608-611. https://doi.org/10.1038/386608a0

Cowan, N. (2001). The Magical Number 4 in Short-Term Memory: A Reconsideration of Mental Storage Capacity. Behavioral and Brain Sciences, 24, 87-185. https://doi.org/10.1017/S0140525X01003922

Luck, S. J., \& Vogel, E. K. (1997). The Capacity of Visual Working Memory for Features and Conjunctions. Nature, 390, 279-281. https://doi.org/10.1038/36846

Shu, H., Cheng, Y. S., \& Zhang, H. C. (1989). A Standardized Set of 235 Pictures: Norms for Name Agreement, Image Agreement, Familiarity and Visual Complexity. Acta Psychology Sinica, 21, 389-396. (In Chinese)

Smith, E. E., Jonides, J., Koeppe, R. A. et al. (1995). Spatial versus Object Working Memory: PET Investigations. Journal of Cognitive Neuroscience, 7, 337-356.

https://doi.org/10.1162/jocn.1995.7.3.337 
Snodgrass, J. G., \& Vanderwart, M. (1980). A Standardized Set of 260 Pictures: Norms for Name Agreement, Image Agreement, Familiarity, and Visual Complexity. Journal of Experimental Psychology: Human Learning and Memory, 6, 174-215. https://doi.org/10.1037/0278-7393.6.2.174

Song, J. H., \& Jiang, Y. H. (2006). Visual Working Memory for Simple and Complex Features-An fMRI Study. Neuroimage, 30, 963-972.

Wheeler, M. E., \& Treisman, A. M. (2002). Binding in Short-Term Memory. Journal of Experimental Psychology: General, 131, 48-64.

https://doi.org/10.1037/0096-3445.131.1.48

$\mathrm{Xu}$, Y. (2002). Limitations of Object-Based Feature Encoding in Visual Short-Term Memory. Journal of Experimental Psychology: Human Perception and Performance, 28, 458-468. https://doi.org/10.1037/0096-1523.28.2.458

Zhang, Q. F., \& Yang, Y. F. (2003). The Determiners of Picture-Naming Latency. Acta Psychology Sinica, 35, 447-454. (In Chinese)

Submit or recommend next manuscript to SCIRP and we will provide best service for you:

Accepting pre-submission inquiries through Email, Facebook, LinkedIn, Twitter, etc. A wide selection of journals (inclusive of 9 subjects, more than 200 journals)

Providing 24-hour high-quality service

User-friendly online submission system

Fair and swift peer-review system

Efficient typesetting and proofreading procedure

Display of the result of downloads and visits, as well as the number of cited articles

Maximum dissemination of your research work

Submit your manuscript at: http://papersubmission.scirp.org/

Or contact psych@scirp.org 